\title{
Comparação entre imunofluorescência indireta e aglutinação direta para o diagnóstico sorológico da leishmaniose tegumentar americana em cães errantes
}

\author{
[Comparison between indirect immunofluorescence and direct agglutination for the serologic diagnosis \\ of American cutaneous leishmaniasis in stray dogs] \\ M.V.C. Lonardoni, F.H.Z.Bernal, T.G.V. Silveira, V. Antunes, U. Teodoro, \\ F.A. Jorge, P.D. Zanzarini \\ Universidade Estadual de Maringá \\ Av. Colombo, 5790 \\ 87.020-900 - Maringá - PR
}

\begin{abstract}
RESUMO
Estudaram-se 92 cães errantes com o objetivo de comparar a imunofluorescência indireta (IFI) e a aglutinação direta (AD) na investigação da leishmaniose tegumentar americana (LTA) canina, no período de outubro de 1999 a novembro de 2001. Os animais foram examinados quanto à presença de lesões e submetidos à intradermorreação de Montenegro (IDRM) e à pesquisa de anticorpos anti-Leishmania por IFI e AD. A IFI apresentou sensibilidade de $78,9 \%$ e especificidade de $93,8 \%$ (título $\geq 40$ ), e a AD sensibilidade de $57,9 \%$ e especificidade de $68,8 \%$ (título $\geq 80$ ). Dois cães apresentavam lesão, mas a pesquisa do parasito foi negativa. A IDRM, realizada em 89 cães, foi positiva em três $(3,4 \%)$. Trinta e quatro cães $(37,0 \%)$ foram positivos para a IFI, $61(66,3 \%)$ para a $\mathrm{AD}$ e $69(75,0 \%)$ para a IFI e/ou a AD. Dos cães com a IFI positiva, sete eram de Floresta, 13 de Maringá, 12 de Leópolis, um de São Jorge do Ivaí e um $(50,0 \%)$ de Campo Mourão. Os resultados sugerem o contato prévio desses animais com o parasito
\end{abstract}

Palavras-chave: cães errantes, leishmaniose tegumentar americana, Paraná

\begin{abstract}
Ninety-two stray dogs were studied in order to compare indirect immunofluorescence (IIF) and direct agglutination (DA) in the investigation of American cutaneous leishmaniasis (ACL), from October 1999 to November 2001. The dogs were evaluated for the presence of lesions, and submitted to the Montenegro skin test (MST) and the search for anti-Leishmania antibodies by IIF and DA. IIF showed $78.9 \%$ sensitivity and $93.8 \%$ specificity (titers $\geq 40$ ), and DA presented $57.9 \%$ sensitivity and $68.8 \%$ specificity (titers $\geq 80$ ). In two dogs there were lesions, but the parasite was not detected. The MST was positive in 3 (3.4\%) out of 89 dogs. Thirty-four (37.0\%) dogs showed anti-Leishmania antibodies through IIF, 61 (66.3\%) through DA, and 69 (75.0\%) through IIF and/or DA. Of the dogs with positive IIF, 7 came from the municipal areas of Floresta, 13 of Maringá, 12 of Leópolis, 1 of São Jorge do Ivai and 1 (50.0\%) of Campo Mourão. These data suggest previous contact of these animals with the parasite.
\end{abstract}

Keywords: stray dogs, American cutaneous leishmaniasis, Paraná State

Recebido em 10 de maio de 2005

Aceito em 24 de novembro de 2006

E-mail: mvclonardoni@uem.br 


\section{Lonardoni et al.}

\section{INTRODUÇÃO}

As leishmanioses, doenças causadas por parasitos do gênero Leishmania transmitidos por flebotomíneos, provocam desde lesões tegumentares até viscerais. Essas doenças constituem problemas de saúde pública, sendo responsáveis por altas taxas de mortalidade e morbidade, principalmente em áreas rurais. No Brasil, a leishmaniose tegumentar americana (LTA) afeta grande número de pessoas e é encontrada em todos os estados (Ministério..., 2005).

No estado do Paraná, a LTA é endêmica em diversos municípios, principalmente no norte e noroeste (Teodoro et al., 1991; Silveira et al., 1994, 1996a, 1999), onde tem sido documentada a presença de cães infectados, além de cães com sorologia positiva (Silveira et al., 1966), principalmente em locais em que ocorre a doença humana (Lonardoni et al., 1993).

Apesar de ser uma zoonose originalmente silvestre, a LTA causada pela Leishmania (Viannia) braziliensis tem sido assinalada em ambientes antrópicos de áreas endêmicas, onde há a possibilidade de animais domésticos, como o cão, serem reservatórios (Falqueto et al., 1986; Pirmez et al., 1988; Reithinger et al., 1999, 2002, Madeira et al., 2003). No entanto, há dúvidas quanto ao verdadeiro papel do cão no ciclo de transmissão do agente.

Considerando a endemicidade da doença no estado do Paraná, os relatos de cães infectados e a possibilidade desses animais participarem na cadeia de transmissão, o objetivo deste trabalho foi comparar a imunofluorescência indireta e a aglutinação direta na investigação a LTA em cães errantes.

\section{MATERIAL E MÉTODOS}

Foram estudados 92 cães errantes, provenientes de municípios das mesorregiões Norte Central Paranaense (Floresta, Maringá, São Jorge do Ivaí), Centro Ocidental Paranaense (Campo Mourão) e Norte Pioneiro Paranaense (Leópolis) (Fig. 1). Os cães, encaminhados ao Biotério Central da Universidade Estadual de Maringá, no período de outubro de 1999 a novembro de 2001, foram examinados quanto à presença de lesões, $\mathrm{e}$ de cada um obteve-se uma amostra de sangue para a realização dos testes sorológicos. Para a padronização dos testes sorológicos foram utilizados soros de 38 cães com lesão e pesquisa direta de Leishmania sp. positiva e de 16 cães normais provenientes de área urbana não endêmica.

A intradermorreação foi realizada em 89 cães, utilizando o Reagente de Montenegro $(40 \mu \mathrm{g} / \mathrm{ml}$ de nitrogênio protéico) produzido no Centro de Produção e Pesquisa em Imunobiológicos (CPPI/SESI/PR), inoculando-se $\quad 0,2 \mathrm{ml}$ intradermicamente na região abdominal do animal. A leitura foi realizada após 48 horas, e a reação considerada positiva quando o diâmetro médio do nódulo foi igual ou superior a $5 \mathrm{~mm}$ (Barbosa et al., 1999; Santos et al., 2005).

A reação de imunofluorescência indireta (IFI) para Leishmania foi realizada conforme Silveira et al. (1990). O antígeno foi preparado a partir de formas promastigotas de $L$. (V.) braziliensis cultivadas em meio 199 suplementado com $10 \%$ de soro bovino fetal. Os soros foram diluídos a partir de 1/20 em razão 2 , e a reação revelada com o conjugado anti-IgG de cão-fluoresceína (fornecido pela FioCruz - Rio de Janeiro). A imunofluorescência indireta para Trypanosoma cruzi foi realizada com antígeno de T. cruzi $\left(\right.$ Biolab $\left.^{1}\right)$ e conjugado anti-IgG de cãofluoresceína.

A reação de aglutinação direta (AD) foi realizada conforme descrito por Garcez et al. (1997), com algumas modificações. Formas promastigotas de $L$. (V.) braziliensis foram cultivadas em meio 199 suplementado com $10 \%$ de soro bovino fetal até atingir a fase estacionária de crescimento. Os parasitos foram lavados cinco vezes $(3.000 \mathrm{xg}, 15$ min, $\left.4^{\circ} \mathrm{C}\right)$ com solução de Locke $(\mathrm{NaCl} 0,15 \mathrm{M}$; $\mathrm{KCl} 5,6 \mathrm{mM} ; \mathrm{CaCl}_{2}$ 2,1 mM; $\mathrm{NaHCO}_{3}$ 2,3 mM; glucose $5,5 \mathrm{mM})$. O sedimento foi ressuspenso a 1/20 (peso/volume) em solução de Locke contendo $0,4 \%$ de tripsina $\left(\right.$ Sigma $\left.^{2}\right)$ a $4^{\circ} \mathrm{C}$ e incubado durante $45 \mathrm{~min}$ a $37^{\circ} \mathrm{C}$. Os parasitos foram novamente lavados $\left(3.000 \mathrm{xg}, 15 \mathrm{~min}, 4^{\circ} \mathrm{C}\right)$ e ressuspensos para a concentração de $2 \times 10^{8}$ promastigotas $/ \mathrm{ml}$.

\footnotetext{
${ }^{1}$ Biolab. Biolab-Mérieux S.A. Rio de Janeiro, RJ, Brasil.

${ }^{2}$ Sigma. Sigma-Aldrich do Brasil Ltda. São Paulo, SP, Brasil.
} 


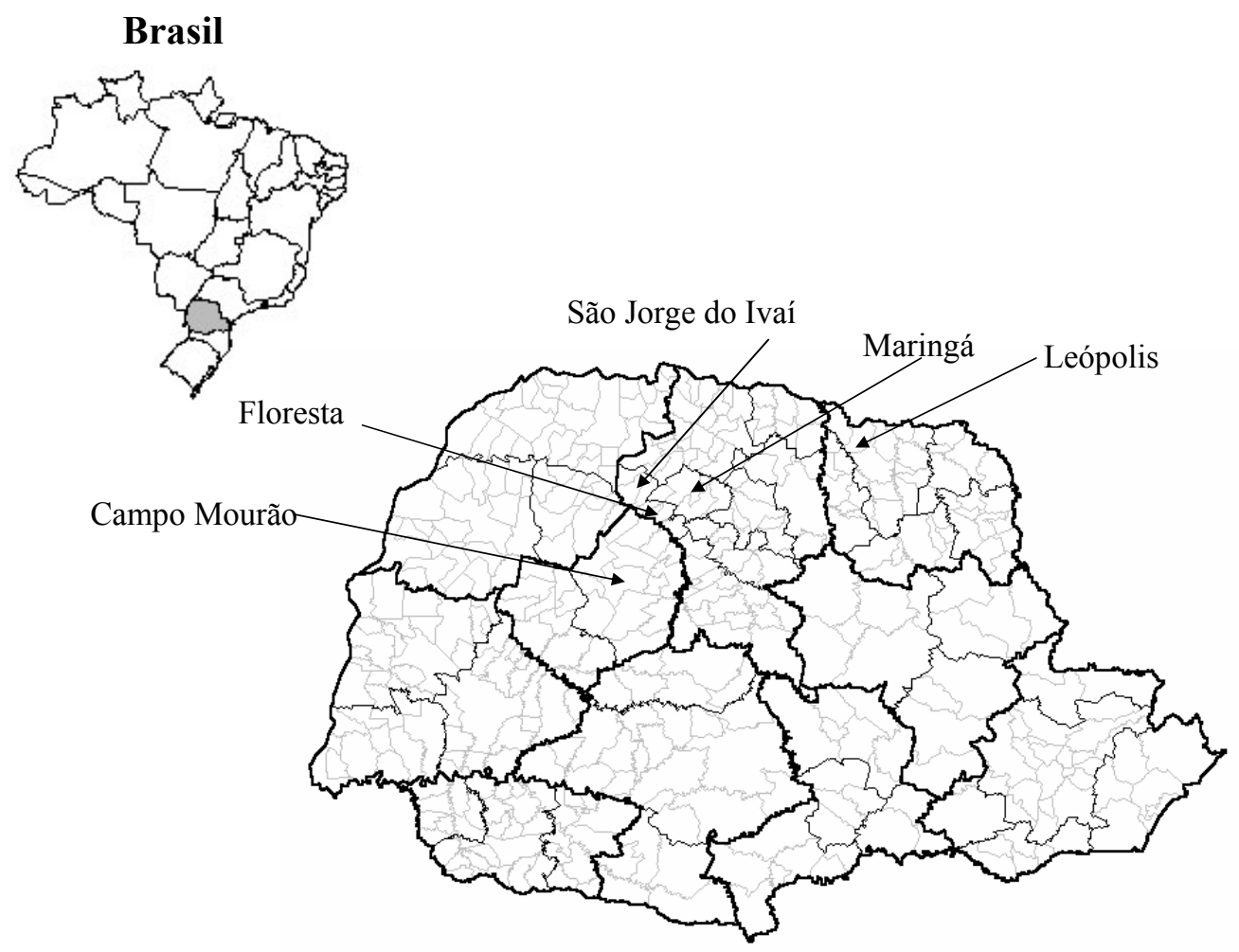

Estado do Paraná

Figura 1. Localização do estado do Paraná e dos municípios de procedência dos 92 cães errantes estudados no período de outubro de 1999 a novembro de 2001.

Adicionou-se igual volume de formaldeído $2 \%$ em solução de Locke e a suspensão foi mantida a $4^{\circ} \mathrm{C}$ overnight. Os parasitos foram lavados três vezes com solução físiológica $(4.000 \mathrm{xg}, 10 \mathrm{~min}$, $4^{\circ} \mathrm{C}$ ) e ressuspensos em solução fisiológica contendo $0,02 \%$ (peso/volume) de Comassie Brilliant Blue (Sigma) ${ }^{2}$, de modo a conter $1 \times 10^{8}$ promastigotas $/ \mathrm{ml}$, mantendo-se sob agitação moderada durante $90 \mathrm{~min}$. Foram centrifugados e lavados três vezes com solução fisiológica $\left(4.000 \mathrm{xg}, 10 \mathrm{~min}, 4^{\circ} \mathrm{C}\right)$. A concentração foi ajustada para $1 \times 10^{8}$ promastigotas $/ \mathrm{ml}$ em solução fisiológica contendo $1 \%$ de formaldeído, e a suspensão filtrada em nylon. As suspensões foram estocadas a $4^{\circ} \mathrm{C}$ em frascos escuros até o uso. Os soros foram inicialmente diluídos a partir de 1/20 em solução diluente (solução fisiológica contendo $1 \%$ de soro bovino fetal e $0,7 \%$ de 2 mercaptoetanol) em microplacas com poços em $\mathrm{V}$, que foram incubadas por $1 \mathrm{~h}$ à temperatura ambiente. Após, adicionou-se igual volume $(50 \mu 1)$ da suspensão de antígeno. Essas microplacas foram mantidas à temperatura ambiente, overnight. Como controle de aglutinação utilizou-se solução diluente. Soros controles positivos e negativos foram incluídos em todas as reações.

Para as reações de IFI e AD nos grupos de cães positivos e normais, calculou-se a mediana dos títulos. Os valores de cortes (títulos significativos) foram estabelecidos a partir dos parâmetros de sensibilidade e especificidade (Ferreira e Ávila, 2001).

\section{RESULTADOS}

Na Fig. 2 mostram-se os resultados obtidos na padronização das técnicas de IFI e AD utilizando soros de cães com LTA e normais. Na IFI, a 
mediana dos títulos do grupo de cães positivos foi 80 , sendo que 30 dos 38 animais apresentaram títulos iguais ou superiores a 40. Considerando como significativo título maior ou igual a 40 (ponto de corte), a sensibilidade foi $78,9 \%$, e a especificidade $93,8 \%$, sendo que apenas um animal normal apresentou título 40. Na AD, a mediana dos títulos do grupo de cães positivos foi 80 , sendo que 22 dos 38 animais apresentaram títulos iguais ou superiores a 80 . Para o ponto de corte em 80, a sensibilidade foi $57,9 \%$. No grupo de 16 animais normais, a mediana foi 40 , sendo que 11 deles tiveram títulos inferiores a 80 , resultando numa especificidade de $68,8 \%$.

\section{IFI}
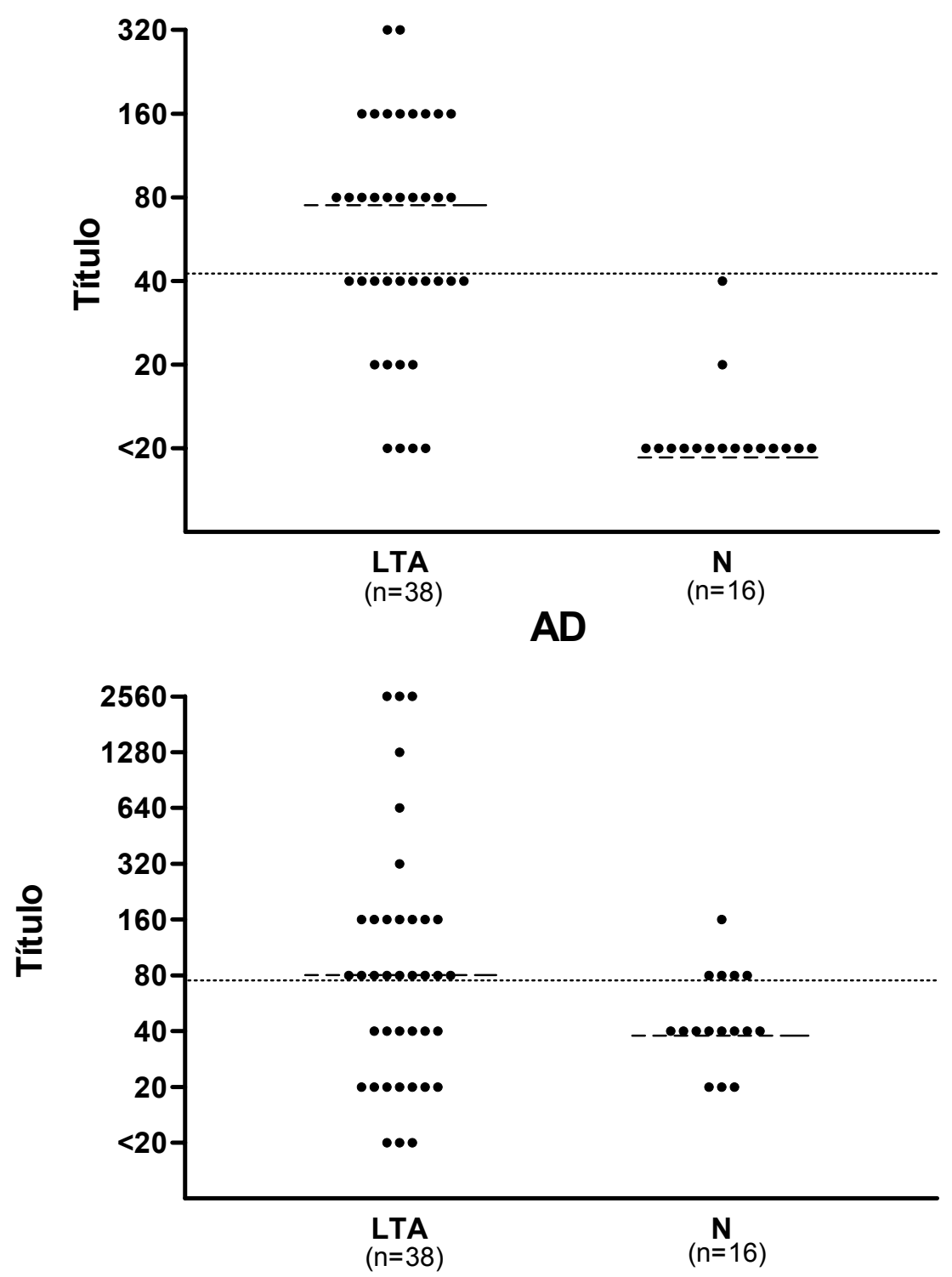

Figura 2. Detecção de anticorpos anti-Leishmania em soros de cães com leishmaniose tegumentar (LTA) e cães normais $(\mathrm{N})$ por imunofluorescência indireta (IFI) e aglutinação direta (AD). Cada símbolo (•) representa a amostra de soro de um animal. A linha pontilhada horizontal representa os valores de corte: 40 para IFI e 80 para AD. As linhas tracejadas representam a mediana dos títulos dos grupos de soros e $n$ é o número de amostras. 
Dos 92 cães estudados, $34(37,0 \%)$ tiveram títulos iguais ou superiores a 40 na IFI, e $61(66,3 \%)$ iguais ou superiores a 80 na $\mathrm{AD}$. A presença de anticorpos anti-Leishmania foi detectada em 69 cães $(75,0 \%)$ pelas técnicas de IFI e/ou AD. A IDRM foi realizada em 89 cães, e três deles $(3,4 \%)$ foram positivos, sendo que dois também foram positivos pela IFI e AD (Tab. 1).

Os soros dos cães que apresentaram títulos significativos na IFI para Leishmania foram testados quanto à reatividade com $T$. cruzi. Somente um cão apresentou título 40 para Leishmania e 80 para T. cruzi. Lesões suspeitas de LTA foram detectadas em dois cães, no entanto a pesquisa direta do parasito foi negativa.

Na Fig. 3 apresenta-se a correlação entre os títulos obtidos na IFI e na $\mathrm{AD}$ nos 92 cães. A copositividade das duas técnicas foi $76,5 \%$; a conegatividade, $39,7 \%$ e a concordância, $53,3 \%$.

Tabela 1. Distribuição dos resultados obtidos na intradermorreação de Montenegro (IDRM), imunofluorescência indireta (IFI) e aglutinação direta (AD) em 92 cães errantes provenientes do norte e noroeste do estado do Paraná, no período de outubro de 1999 a novembro de 2001

\begin{tabular}{clcc}
\hline IFI & \multicolumn{1}{c}{$\begin{array}{c}\text { IDRM } \\
(\mathrm{n}=89)\end{array}$} & Positivo & AD $(\mathrm{n}=92)$ \\
\cline { 3 - 4 } & & \multicolumn{2}{c}{ Negativo } \\
\hline \multirow{2}{*}{ Positivo } & Positivo $(\mathrm{n}=2)$ & 22 & 0 \\
$(\mathrm{n}=34)$ & Negativo $(\mathrm{n}=30)$ & 2 & $8^{*}$ \\
& NR $(\mathrm{n}=2)$ & 1 & 0 \\
\hline \multirow{2}{*}{ Negativo } & Positivo $(\mathrm{n}=1)$ & 34 & 0 \\
$(\mathrm{n}=58)$ & Negativo $(\mathrm{n}=56)$ & 0 & 22 \\
& NR $(\mathrm{n}=1)$ & $61^{*}$ & 1 \\
\hline
\end{tabular}

$\mathrm{NR}=$ não realizado; * IFI e/ou AD positivas: 69.

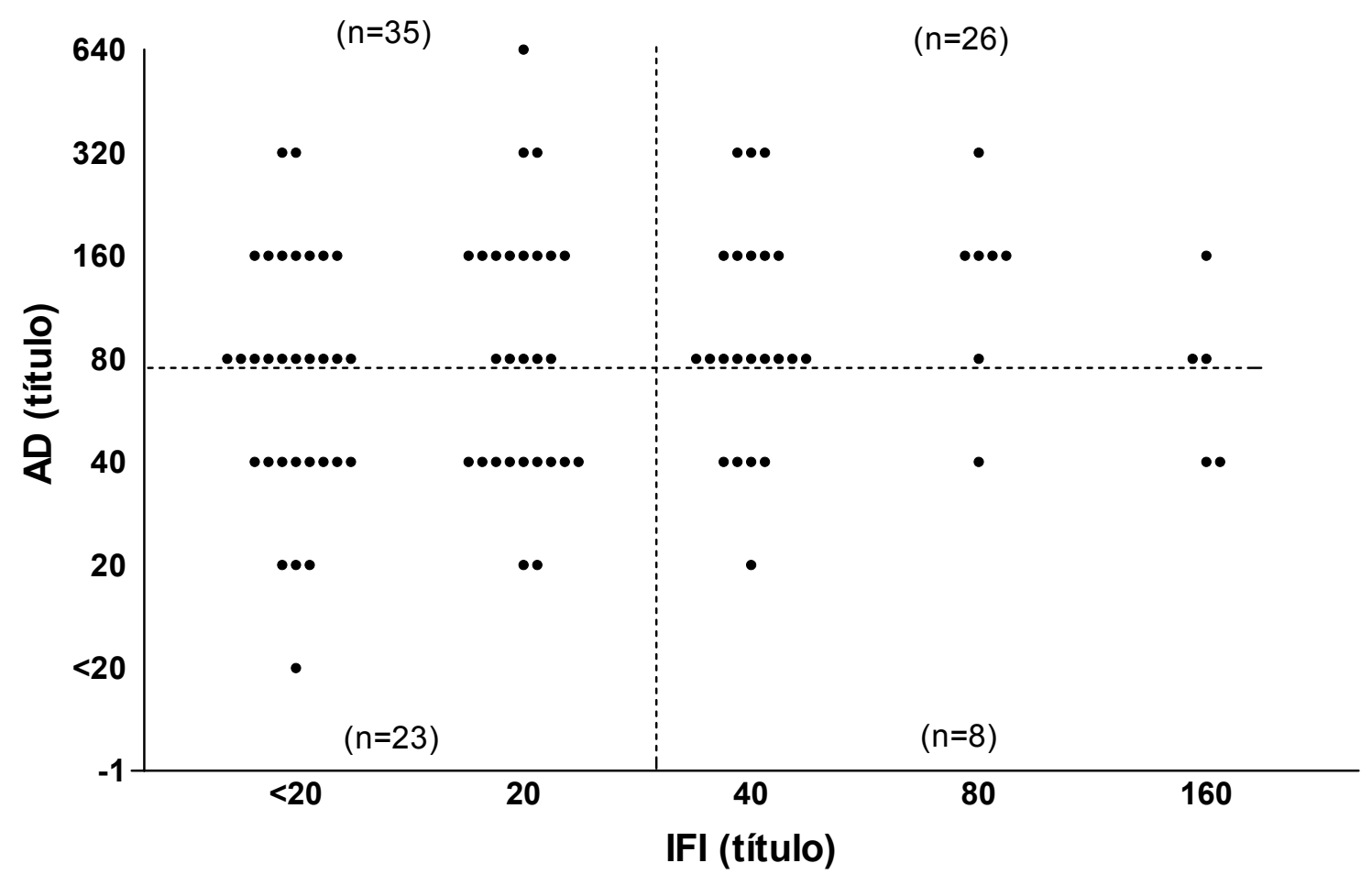

Figura 3. Títulos de anticorpos anti-Leishmania obtidos na imunofluorescência indireta (IFI) e aglutinação direta (AD) nos 92 cães errantes estudados. Cada símbolo $(\bullet)$ representa uma amostra de soro. As linhas pontilhadas representam os valores de corte: 40 para IFI (vertical) e 80 para AD (horizontal). 
A IFI foi positiva em sete $(7 / 32 ; 21,9 \%)$ dos cães de Floresta, $13(13 / 32 ; 40,6 \%)$ de Maringá, 12 $(12 / 18 ; 66,7 \%)$ de Leópolis, um $(1 / 8 ; 12,5 \%)$ de São Jorge do Ivaí e um $(1 / 2 ; 50,0 \%)$ de Campo Mourão.

Foi possível acompanhar 10 dos 34 cães que apresentaram IFI positiva (Tab. 2). A IFI foi repetida após intervalo de tempo que variou de dois a 13 meses e, em alguns casos, foi repetida em dois momentos. Em sete cães os títulos permaneceram significativos (quatro de Leópolis, dois de Maringá, um de Floresta e um de São Jorge do Ivaí). Nenhum cão desenvolveu lesão sugestiva de LTA no período de acompanhamento.

Tabela 2. Acompanhamento sorológico por imunofluorescência indireta de 10 cães que apresentaram inicialmente títulos de anticorpos anti-Leishmania iguais ou superiores a 40

\begin{tabular}{|c|c|c|c|c|c|c|c|}
\hline \multirow{3}{*}{ Cão } & \multirow{3}{*}{ Procedência } & \multicolumn{6}{|c|}{ Título da IFI } \\
\hline & & \multicolumn{6}{|c|}{ Tempo (meses) } \\
\hline & & 0 & 2 & 3 & 5 & 9 & 13 \\
\hline 5 & Leópolis & 160 & & & & & 40 \\
\hline 50 & Leópolis & 40 & & 40 & & 40 & \\
\hline 52 & Leópolis & 40 & & 20 & & 40 & \\
\hline 62 & São Jorge do Ivaí & 80 & 40 & & & & \\
\hline 106 & Maringá & 40 & & & 40 & & \\
\hline 108 & Floresta & 40 & & & $<20$ & & \\
\hline 110 & Maringá & 80 & & & 20 & & \\
\hline 121 & Maringá & 80 & & & 40 & & \\
\hline 122 & Leópolis & 80 & & & 80 & & \\
\hline 129 & Floresta & 40 & & & 20 & & \\
\hline
\end{tabular}

\section{DISCUSSÃO}

A pesquisa de anticorpos tem sido uma ferramenta útil tanto para o diagnóstico quanto para inquéritos epidemiológicos de várias doenças. Técnicas que utilizam reagentes espécie-específicos (conjugados antigamaglobulina), como a imunofluorescência indireta e enzimaimunoensaio, têm sido bastante utilizadas para a sorologia em humanos e animais. No entanto, muitas vezes existem dificuldades em relação à obtenção desses reagentes específicos para a espécie animal a ser estudada, seja pelo custo ou pela indisponibilidade no mercado, a exemplo dos animais silvestres. Por não necessitar de reagentes espécie-específicos, a $\mathrm{AD}$ pode ser útil na detecção da infecção em diferentes espécies animais.

Neste trabalho, observou-se que a especificidade da $\mathrm{AD}$ foi inferior à encontrada na IFI. No entanto, a $\mathrm{AD}$ pode ser utilizada na triagem sorológica de cães ou na investigação de outros animais para os quais não há conjugados disponíveis. A AD foi utilizada por Garcez et al. (1997) para a detecção de resposta humoral em macacos experimentalmente infectados com Leishmania e por Bezerra et al. (1996), para a detecção de infecção por $L$. (V.) braziliensis em cães, no estado do Ceará. Esses últimos autores encontraram $11 \%$ de resultados falso-positivos e recomendaram a utilização da $\mathrm{AD}$ para a investigação da infecção por Leishmania em regiões onde se possa excluir a leishmaniose visceral e a doença de Chagas.

A LTA é endêmica no norte/noroeste do estado do Paraná onde é causada por $L$. ( $V$.) braziliensis (Silveira et al., 1996a; 1999). Nessa região, já foi relatada a presença de cães infectados com $L$. (V.) braziliensis (Lonardoni et al., 1993). Poucos cães tiveram a IDRM positiva $(3,4 \%)$, contrastando com os resultados relatados por Barbosa et al (1999), que encontraram 8,8\% de positividade no teste intradérmico, e Santos et al. (2005), que obtiveram positividade de 10,2\% em cães de área semi-urbanizada. Esses autores empregaram reagentes com concentrações protéicas superiores à usada neste trabalho, o que poderia explicar as diferenças de positividade encontradas.

Neste estudo, a positividade da IFI foi $37,0 \%$ e da $\mathrm{AD}$ foi $66,3 \%$, e o percentual dos cães que apresentaram anticorpos anti-Leishmania por pelo menos uma das técnicas foi elevado $(75,0 \%)$. Apenas um dos animais apresentou anticorpos anti-T. cruzi em títulos superiores aos 
anti-Leishmania, o que sugere a doença de Chagas; no entanto, essa possibilidade não foi investigada. Embora a reatividade sorológica cruzada entre Leishmania sp. e T. cruzi esteja bem estabelecida, pouco se conhece sobre a influência de outros microrganismos que infectam esses animais, nos resultados de testes para a pesquisa de anticorpos anti-Leishmania.

Os cães com sorologia positiva eram de municípios do estado do Paraná onde tem ocorrido casos humanos de LTA. Segundo os dados do SESA/ISEP/CIDS/DSI/SINAN/PR, no período 2001/2002, na $15^{\text {a }}$ Regional de Saúde, à qual pertencem os municípios de Floresta, Maringá, São Jorge do Ivaí, ocorreram 101 casos humanos confirmados de LTA. Na $18^{\mathrm{a}}$ Regional de Saúde, a qual pertence o município de Leópolis, 58 casos humanos foram confirmados, enquanto na $11^{\text {a }}$ Regional de Saúde (Campo Mourão) foram 53 casos humanos. Vários estudos têm mostrado alta reatividade sorológica para Leishmania em cães de áreas endêmicas. Assim, Pirmez et al. (1988), no estado do Rio de Janeiro, registraram 32 cães com sorologia positiva entre 35 investigados. Marzochi et al. (1988), em zona endêmica do Rio de Janeiro, encontraram $22,9 \%$ de positividade entre 48 cães analisados, e Silveira et al. (1996b), na região noroeste do estado do Paraná, registraram 24 $(18,2 \%)$ cães com sorologia positiva entre 132 investigados. Já Savani et al. (1999), em inquérito sorológico realizado em cães errantes no estado de São Paulo, onde havia relato de casos humanos autóctones de LTA, não encontraram cães positivos entre 973 analisados.

O acompanhamento sorológico realizado em 10 cães mostrou que sete deles permaneceram com títulos significativos de anticorpos. Embora eles não tenham desenvolvido lesão sugestiva de LTA no período de acompanhamento, não se descarta a possibilidade de formas subclínicas da LTA canina. A sorologia positiva pode ser um bom indicativo da infecção em cães (Barbosa et al., 1999). Santos et al. (2005), em estudo realizado em Paracambi, estado do Rio de Janeiro, verificaram a ocorrência de LTA canina sintomática e subclínica simultânea aos casos humanos e sugeriram que o cão pode desempenhar algum papel na cadeia de transmissão dessa doença. Zanzarini et al. (2005), em estudo realizado no norte/noroeste do estado do Paraná, encontraram cães com sorologia positiva em todas as localidades onde ocorreram casos humanos de LTA.

Embora a AD apresente índices de sensibilidade e de especificidade inferiores aos da IFI, ela pode ser uma alternativa para o estudo sorológico de animais, no campo, pela simplicidade de execução. A sorologia positiva para Leishmania em cães errantes em áreas onde ocorrem casos humanos de LTA sugere que houve a circulação do agente e que estes animais tiveram contato com o parasito. Contudo, novos estudos devem ser conduzidos no sentido de esclarecer a participação dos cães na epidemiologia da LTA no Paraná.

\section{REFERÊNCIAS BIBLIOGRÁFICAS}

BARBOSA, G.M.S.; MARZOCHI, M.C.A.; MASSARD, C.L. et al. Aspectos epidemiológicos da leishmaniose tegumentar americana em cães, no Município de Paraty, Estado do Rio de Janeiro, Brasil. Cad. Saúde Públ., v.15, p.641-646, 1999.

BEZERRA, H.S.; VIANA, J.R.; TEXEIRA, M.J. et al. Evaluation of direct agglutination tests in the detection of Leishmania (Viannia) braziliensis in possible reservoirs of cutaneous American leishmaniasis in the state of Ceará. Rev. Soc. Bras. Med. Trop., v.29, p.181-184, 1996.

FALQUETO, A.; COURA, J.R.; BARROS, G.C. et al. Participação do cão no ciclo de transmissão da leishmaniose tegumentar no Município de Viana. Estado do Espírito Santo, Brasil. Mem. Inst. Oswaldo Cruz, v.81, p.155-163, 1986.

FERREIRA, A.W.; ÁVILA, S.M. Sorologia; importância e parâmetros. In: FERREIRA, A.W.; ÁVILA, S.M (Eds.). Diagnóstico laboratorial das principais doenças infecciosas e autoimunes. 2.ed. Rio de Janeiro: Guanabara Koogan, 2001. p.1-8.

GARCEZ, L.M.; SILVEIRA, F.T.; HARITH, A. et al.. Experimental cutaneous leishmaniasis. IV. The humoral response of Cebus apella (Primates: Cebidae) to infections of Leishmania (Leishmania) amazonensis, L. (Viannia) lainsoni and L. (V.) braziliensis using the direct agglutination test. Acta Tropica, v.68, p.65-76, 1997. 


\section{Lonardoni et al.}

LONARDONI, M.V.C.; TEODORO, U.; ARRAES, S.M.A.A. et al. Nota sobre leishmaniose canina no noroeste do Estado do Paraná, sul do Brasil. Rev. Saúde Públ., v.27, p.378-379, 1993.

MADEIRA, M.F.; UCHOA, C.M.; LEAL, C.A. et al. Leishmania (Viannia) braziliensis em cães naturalmente infectados. Rev. Soc. Bras. Med. Trop., v.36, p.551-555, 2003.

MARZOCHI, M.C.A.; BARBOSA-SANTOS, E.G.O. Evaluation of a skin test on the canine mucocutaneous leishmaniasis diagnosis. Mem. Inst. Oswaldo Cruz, v.83, p.391-392, 1988.

MINISTÉRIO DA SAÚDE. Série Histórica de Casos de Doenças de Notificação Compulsória por doença (1980 - 2003). 25/02/2005.

http://dtr2001.saude.gov.br/svs/epi/situacao_doe ncas/transmissiveis $00 . \mathrm{htm}$

PIRMEZ, C.; COUTINHO, S.G.; MARZOCHI, M.C.A. et al. Canine American cutaneous leishmaniasis: a clinical and immunological study in dogs naturally infected with Leishmania braziliensis in an endemic area of Rio de Janeiro, Brazil. Am. J. Trop. Med. Hyg., v.38, p.52-58, 1988.

REITHINGER, R.; DAVIES, C.R. Is the domestic dog (Canis familiaris) a reservoir host of American cutaneous leishmaniasis? A critical review of the current evidence. Am. J. Trop. Med. Hyg., v.61, p.530-541, 1999.

REITHINGER, R.; LAMBSON, B.E.; BARKER, D.C. et al. Leishmania (Viannia) ssp. dissemination and tissue tropism in naturally infected dogs (Canis familiaris). Trans. R. Soc. Trop. Med. Hyg., v.96, p.76-82, 2002.

SANTOS, G.P.L.; SANAVRIA, A.; MARZOCHI, M.C.A. et al. Prevalência da infecção canina em áreas endêmicas de leishmaniose tegumentar americana, do município de Paracambi, Estado do Rio de Janeiro, no período entre 1992 e 1993. Rev. Soc. Bras. Med. Trop., v.38, p.161-166, 2005.

SAVANI, E.S.M.M.; GALATI, E.A.B.; CAMARGO, M.C.G.O. et al. Inquérito sorológico sobre leishmaniose tegumentar Americana em cães errantes no Estado de São Paulo, Brasil. Rev. Saúde Públ., v.33, p.629-632, 1999.

SILVEIRA， T.G.V.; ARRAES， S.M.A.A.; PEREIRA, D.S. et al.. Avaliação da reação de imunofluorescência indireta para leishmaniose tegumentar americana em pacientes de região noroeste do Estado do Paraná - Brasil. Rev. Unimar, v.12, p.177-178, 1990.

SILVEIRA, T.G.V.; TEODORO, U.; LONARDONI, M.V.C. et al. Investigação epidemiológica de leishmaniose tegumentar em área endêmica no Estado do Paraná, sul do Brasil. Mem. Inst. Oswaldo Cruz, v.89, p.181, 1994.

SILVEIRA, T.G.V.; TEODORO, U.; LONARDONI, M.V.C. Aspectos epidemiológicos da leishmaniose tegumentar em área endêmica do Estado do Paraná, sul do Brasil. Cad. Saúde Públ., v.12, p.37-45, 1996a.

SILVEIRA, T.G.V.; TEODORO, U.; LONARDONI, M.V.C. et al. Investigação sorológica em cães de área endêmica de leishmaniose tegumentar, no Estado do Paraná, sul do Brasil. Cad. Saúde Públ., v.12, p.89-93, 1996b.

SILVEIRA, T.G.V.; ARRAES, S.M.A.A.; BERTOLINI, D.A. et al. Observações sobre o diagnóstico laboratorial e a epidemiologia da leishmaniose tegumentar americana no Estado do Paraná, sul do Brasil. Rev. Soc. Bras. Med. Trop., v.32, p.413-23, 1999.

TEODORO, U.; SPINOSA, R.P.; LA SALVIA FILHO, V. et al. Da necessidade de se adotar e divulgar esquemas terapêuticos, para tratamento de leishmaniose tegumentar no Paraná. Rev. Inst. Med. Trop. São Paulo, v.33, p.199-204, 1991.

ZANZARINI, P.D.; SANTOS, D.R.; SANTOS, A.R. et al. Leishmaniose tegumentar americana canina em municípios do norte do Estado do Paraná, Brasil. Cad. Saúde Públ., v.21, p.19571961, 2005. 